Research Article

\title{
Bionic Design and Parameter Optimization of Rotating and Fixed Stem- and Leaf-Cutting Devices for Carrot Combine Harvesters
}

\author{
Han Tang $\mathbb{D}$, Yeming Jiang $\mathbb{i}$, Jinwu Wang $\mathbb{B}$, Rui Guan, and Wenqi Zhou \\ College of Engineering, Northeast Agricultural University, Harbin 150030, China \\ Correspondence should be addressed to Jinwu Wang; jinwuw@neau.edu.cn
}

Received 5 September 2020; Revised 10 January 2021; Accepted 16 January 2021; Published 27 January 2021

Academic Editor: Georgios I. Giannopoulos

Copyright (c) 2021 Han Tang et al. This is an open access article distributed under the Creative Commons Attribution License, which permits unrestricted use, distribution, and reproduction in any medium, provided the original work is properly cited.

\begin{abstract}
To solve the problems of the high rhizome damage and low net cutting during carrot combine harvesting, the following research was performed. The designed carrot stem- and leaf-cutting device was taken as the research object, and a bionic design idea was adopted. MATLAB software was used to extract and optimize the tibial curve of the mantis forelimb, and its shape was applied to the cutting edges of a single-disc rotating cutter and a straight fixed cutter, whose key structural parameters were determined. The kinematic and dynamic models of the cutter, stems, and leaves were established to explore the critical conditions of smooth cutting. A single-factor experiment was performed. The results show that the rhizome damage and the stems and leaf net cutting increased when the rotation speed of the clamping conveyor pulley increased. The flatness of the cutting surface first increased and subsequently decreased. At a speed of $102 \mathrm{r} / \mathrm{min}$, the rhizome damage was $2.86 \%$, the net cutting of stems and leaves was $92.82 \%$, and the flatness of the cutting surface was $85.39 \%$. The net cutting of stems and leaves and the flatness of the cutting surface increased as the disc cutter speed increased, while the rhizome damage decreased. When the rotation speed reached $165 \mathrm{r} / \mathrm{min}$, the rhizome damage, the net cutting of stems and leaves, and the flatness of the cutting surface were $1.97 \%, 89.59 \%$, and $91.48 \%$, respectively. The bench test and field experiment results showed that the cutting performance of the optimized bionic cutter group is significantly better than that of the conventional knife group. The rhizome damage, net cutting of stems and leaves, and flatness of the cutting surface were $4.01 \%, 92.05 \%$, and $84.05 \%$, respectively, which meet the agronomic requirements for carrot harvesting.
\end{abstract}

\section{Introduction}

Carrot is a typical rhizomatous cash crop whose planting area and yield in China rank first in the world $[1,2]$. While carrot harvesting is mainly manual, potato harvesters are used in some areas to harvest carrots in China [3]. This semimechanized harvesting method can complete the primary processes such as deep loosening and digging, but the subsequent processes, including stem cutting and fruit collection, remain manually completed, which has low efficiency and poor reliability and directly affects the economic value of carrots after harvest $[4,5]$. Carrots rot easily, when the stems and leaves are too long after cutting; however, cutting them too short causes serious damage to the roots and stem. Therefore, designing high-quality and efficient stem- and leaf-cutting devices is important for ensuring the quality of carrot combine harvesting.
Scholars in other countries have studied advanced technology for carrot combine harvesting, and such harvesters demonstrate greater efficiency, higher quality, and intelligence and feature reduced damage [6]. Representative models such as the Kubota $\mathrm{CH}-201 \mathrm{C}$ carrot harvester from Japan and the ASA-LISF COMBI MINI traction type carrot harvester from Denmark [7-9] are unsuitable for large-scale application in China due to large differences in agricultural planting modes and soil types. In contrast, Chinese scholars have conducted less research on carrot combine harvesters. For example, the knapsack-type carrot combine harvester developed by Wang et al. [10] can complete multiple processes simultaneously, including loosening, extracting, clearing, cutting, and gathering. In research into carrot stem and leaf cutting, the main cutting types are divided into disc cutters and drag rods. The double row self-propelled carrot combine harvester developed by Jin et al. [11] adopted a 
double disc cutting device that rotates at relatively high speeds to complete the carrot cutting process. The speed is adjustable based on the forward speed of the harvester, but vibration generated by the cutter rotation can easily degrade the cutting effect. Zeng et al. [12] analyzed the influence of relevant parameters on the kinematic characteristics of the pulling rod and developed a pulling rod cutting device, but its overall structure is complex and can greatly damage carrot rhizomes during cutting. Wang et al. [13] designed a single-disc opposite cutting device that can achieve rapid carrot rhizomes cutting, but this approach still has high rhizome damage and low net cutting, and its performance requires further optimization.

Various problems can occur during the harvesting process, such as the high rhizome damage, low net cutting of stems and leaves, and uneven cutting surfaces when cutting with a conventional toothed cutter [14, 15]. Based on this background, this study adopts an author-designed carrot stem- and leaf-cutting device as the research object. The structural parameters of the rotating and fixed cutters were optimized to achieve efficient carrot stems and leaf cutting by imitating the forelimb curve of the mantis. In the remainder of this paper, first, the working principle and chief structure of the cutter and carrot stem and leaf kinematics and dynamics model are established. Next, the critical conditions for smooth cutting are explored, and the main factors affecting cutting performance are identified. Then, the rationality and feasibility of the designed components are verified by single-factor bench tests, comparative tests, and field experiments to provide a reference for the improvement and performance optimization of the key components of a carrot combine harvester.

\section{Materials and Methods}

2.1. Overall Structure and Working Principle of the Carrot Combine Harvester. As shown in Figure 1, a knapsack-type carrot combine harvester is composed mainly of a suspension frame assembly, an eccentric vibration loosening shovel, a profiling stalk pulling device, a clamping conveyor belt assembly, a flexible soil cleaning device, a stem- and leafcutting device, a gearbox, and other components. The frame assembly is attached to the side of a tractor via a three-point suspension, and the position and angle of the frame are controlled by a hydraulic cylinder to facilitate carrot ridge harvesting. Several sets of electric motors are fixed to the driving end of the eccentric vibration loosening shovel and the profiling straw-pulling device to ensure the smooth operation of each part. The loosening shovel is mounted under the frame and uses eccentric vibration to loosen the soil between ridges. The profiling stalk pulling device is composed of oppositely rotating grazers that can extract carrot stems and leaves while conforming to the terrain. The clamping conveyor belt assembly is composed of two sets of national standard B-belts and 24 pairs of tension wheels to smooth the soil cleaning and cutting processes of carrot stems and leaves. Two sets of soil cleaning devices are made of flexible coiled steel wire arranged in the middle and lower part of the clamping conveyor belt assembly; these can be driven and self-rotating to clean soil while continuously conveying carrots. The stem- and leaf-cutting device is arranged at the top of the frame, which is composed of a top pulling alignment system, a rotating cutter, and a fixed cutter. After aligning the carrot roots and stems, the singledisc rotating cutter rotates at high speed and cooperates with the straight fixed cutter to cut and separate the rhizome quickly. The components of this light and simplified frame configuration are connected during assembly; the overall machine structure is compact, simple, and lightweight. Multiple monomer lines can be added to the carrot harvesting operation to adapt it to different environments, improve the versatility and flexibility of the machine operation, and improve the operational efficiency and quality of carrot harvesting $[16,17]$.

The combined harvest process is mainly composed of five series links: vibration loosening, stem supporting extraction, clamping and conveying, flexible soil cleaning, and alignment cutting. During normal operation, the entire machine is loaded on the side of the tractor, and the working position is adjusted by the hydraulic system according to the size of the machine and the environment. The power is transmitted to the gearbox through the multistage transmission system of the engine, which drives the clamping conveyor belt assembly and the stem- and leaf-cutting device to smoothly work. The soil between ridges is loosened by an eccentric vibration loosening shovel, and the stem supporting extraction device is used to support the fallen carrot stems and leaves. The entire carrot rhizome is pulled out from the soil and continuously transported to the clamping conveyor belt assembly; the soil attached to the carrot surface is removed by the flexible steel wire. When it is transported to the cutting area, the single-disc rotating cutter and straight fixed cutter cooperate to separate the stems and leaves. Then, the carrot falls into the collecting box, whose stems and leaves are scattered backward. All parts work together to complete a series of processes at once, which can effectively improve the quality and efficiency of the carrot harvest.

\subsection{Structure Optimization of the Stem-and Leaf-Cutting Device}

2.2.1. Structure and Working Principle of the Stem-and LeafCutting Device. As the core working part of the harvester, the stem- and leaf-cutting device aligns the carrot stems and leaves and cuts them smoothly. The cutting performance directly affects the economic value of the carrots after harvest. As shown in Figure 2, the cutting device is mainly composed of aligning base plates (left and right plates), an aligning belt, the rotating and fixed cutter (a single-disc rotating cutter and a straight fixed cutter), opposite wheel assembly (master-slave wheel, tension wheel, and standard belt), and a disc cutter gearbox. The single-disc rotating cutter derives power from the gearbox. The gear shaft and the single-disc rotating cutter are screwed together, ensuring that the disc cutter rotates with the shaft. The left and right alignment base plates are fixed to the frame by brackets. The 


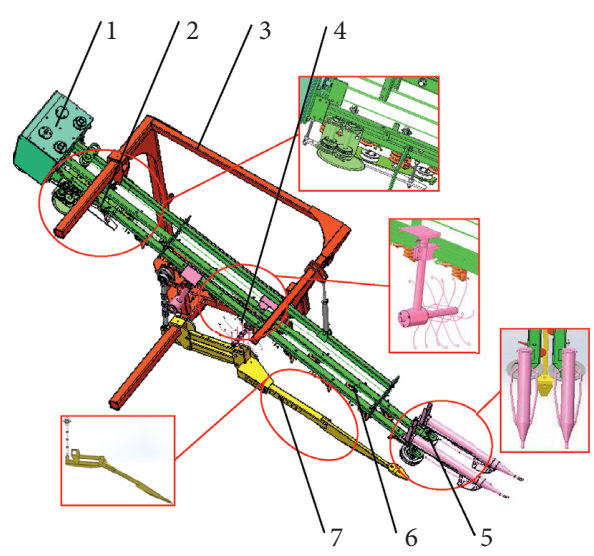

(a)

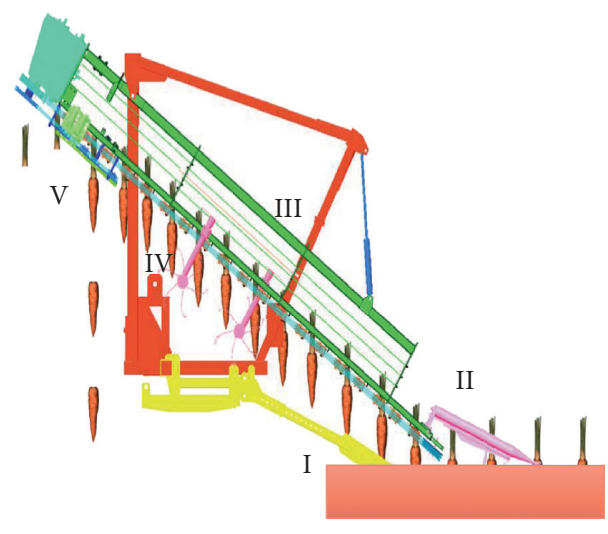

(b)

FIGURE 1: Knapsack-type carrot combine harvester. (a) Overall structure: (1) gearbox; (2) stem- and leaf-cutting device; (3) frame assembly; (4) flexible soil cleaning device; (5) profiling stem pulling device; (6) clamping conveyor belt assembly; (7) eccentric vibration loosening shovel. (b) Working process: (I) vibration loosening process; (II) stem supporting extraction process; (III) clamping and conveying process; (IV) flexible soil cleaning process; (V) alignment cutting process.

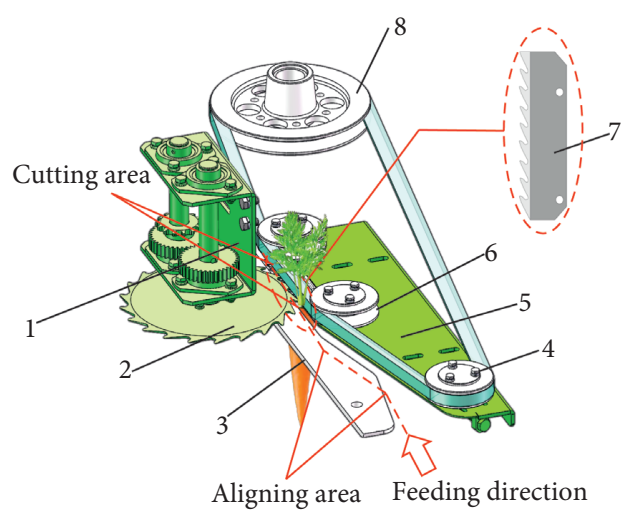

FIGURE 2: Alignment cutting process: (1) disc cutter gearbox; (2) single-disc rotating cutter; (3) alignment left base plate; (4) alignment slave belt; (5) alignment right base plate; (6) alignment tension wheel; (7) straight fixed cutter; (8) alignment master wheel.

alignment belt auxiliary pulley is screwed to the aligning right base plate, which is driven by the gearbox, while the straight cutter is fixed behind the alignment right base plate and overlaps the disc cutter.

During stem and leaf gathering, guiding, and cutting, the carrots are transported up to the aligning area. The alignment belt and clamping conveyor belt move synchronously, causing the carrot stems and leaves to align in the aligning area. The distance between the two aligned substrates allows the carrot stems and leaves to pass through but not the rhizome. The oblique length difference is formed by the carrot stem and leaf channel between the two alignment base plates and the clamping conveyor belt assembly. Under their joint action, carrot stems and leaves with different initial clamping positions are gathered and pulled up to complete the gathering and aligning operation. The pulled carrots are transported to the single rotating disc cutter, which forms a cutting area with the straight fixed cutter to complete stem and root separation.
2.2.2. Bionic Design and Parameter Optimization of the Rotating and Fixed Cutter. As the core working parts of the stem- and leaf-cutting device, the rotating and fixed cutter (single-disc rotating cutter and straight fixed cutter) directly affect the rhizome damage, net cutting of stems and leaves, and flatness of the cutting surface. Finding a reasonable design for the structural size and overlapping length of the two cutters is an effective method to improve the overall operational quality. The serrated cutter has a strong ability to clamp the stem and has good cutting quality and the lowest cutting resistance; the stem and leaf can be easily sawn open by the blade and cut off gradually [18]. As one of the best predators in the insect kingdom, the mantis has sharp serrated barbs on its forelegs that can quickly grasp and hold a prey $[19,20]$. The serrated structure shape of these forefeet has important guiding significance to optimize carrot cutters.

Based on bionics theory, using the mantis forelimb as a prototype, a similar serrated curve was applied to the rotating and fixed cutters by extracting the external contour curve of the mantis tibia to achieve a high-efficiency cutting effect. The stereomicroscope image in Figure 3(a) shows the contour structure of a sample mantis forelimb. Based on the Canny algorithm [21], the Gaussian filter function command in MATLAB software was used to eliminate noise from the original image, the Sobel algorithm was used to detect the edges of the image, and the nonmaximum suppression was used to suppress all except the maximum gradient values [22]. Finally, the lag threshold processing command, with the upper threshold set to 120 and the lower threshold set to 100 , was used to complete the edge extraction of the mantis forelimb tibia. The obtained contour curve has a clear and complete line that is consistent with the external contour of the curvature of a real mantis tibia.

Due to the complex structure of the cutting gear of the forelimb tibia of mantis, the entire curve cannot be accurately expressed by a single function. To fit the optimized curve more clearly, the curves are marked in different colors 


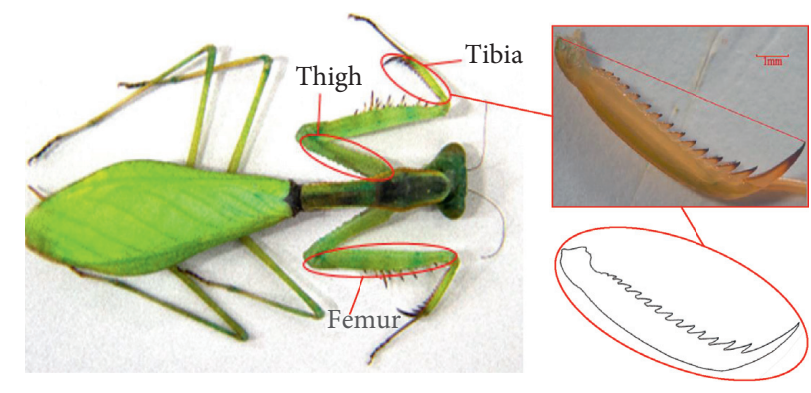

(a)

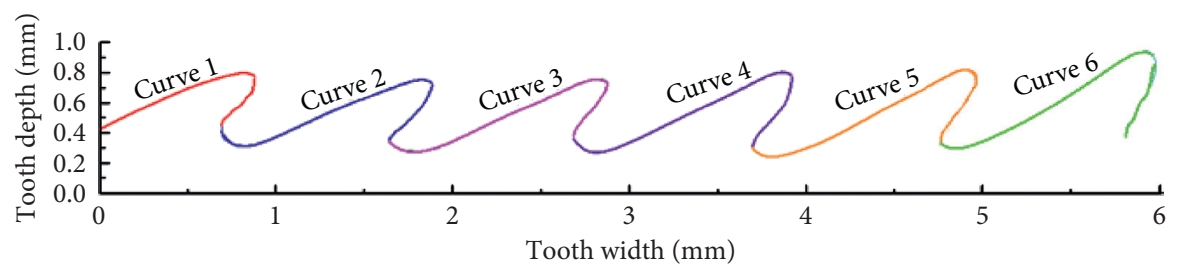

(b)

FIgURE 3: (a) Extraction and (b) division of the cutting-tooth curve of the mantis forelimb.

and drawn in the same coordinate system. According to the principle of curve continuity, the single cutting-tooth curve of the tibia of the mantis forelimb is divided into six segments based on the monotonicity principle of the $x$-axis (named curves 1-6) and divided into a cutting edge curve (ascending curve) and a supporting edge curve (descending curve), as shown in Figure 3(b).

As Figure 3(b) shows, curves 1-6 have similar upward and downward trends. Curves 1 and 2 are relatively gentle in the ascending stage and subsequently rapidly drop to the next curve after reaching the peak value. Curves 4 and 6 are concave in the rising stage, especially curve 6 , which decreases sharply after reaching the peak value. The lengths of the cutting teeth of the forelimb tibia are controlled by the long ascending stage of the six curves, making it convenient for a mantis to cut its prey. Compared with the first half of each curve, which rises slowly, the second half decreases sharply, providing good support for the cutting teeth when cutting prey; this shape ensures the strength of the cutting teeth and increases their sharpness.

On this basis, curves 1-6 were fitted, analyzed, and drawn in the same coordinate system; then, the corresponding fitting curve equations were obtained, as depicted in Figure 4, which shows that, except for the fitting variance $R^{2}$ of the supporting edge of curve 6 , the fitting variance $R^{2}$ of the other curves is greater than 0.95 , and the absolute value of the residual error of each curve is less than 0.06 . The closer the fitting variance is to 1 , the higher the similarity between the fitting curve and the original curve is and the better the fitting effect is. Therefore, the least squares method can be used to fit the cutting teeth curves of the mantis tibia.

To further compare the performance of each cutting tooth, the second derivative and curvature variation law of each curve were analyzed to identify the optimal cutting teeth and calculate the second derivative of the function for curves 1-6, as shown in Figure 5(a). Since the purpose of the long sides of the mantis forelimb cutting teeth is to cut prey, to compare and analyze the cutting effect of the cutting teeth, the second derivative curve of the second half of curves 1 to 6 is hidden, as shown in Figure 5(b). When the second-order function is greater than zero, the curve is convex; otherwise, it is concave. As Figure 5(b) shows, the second-order function values of curves 1-6 continuously fluctuate up and down from 0 ; i.e., all curves are continuously concave or convex, among which the secondorder function values of curves 2, 3, and 4 fluctuate less; thus, those curves are smoother. When this type of curve is applied to the cutting edge of the cutter, the cutting edges of the object should be smoother after cutting.

Based on the second derivative, to more accurately compare and analyze the cutting performance of cutting teeth 2 to 4 , the optimal cutting teeth are selected, and the curvature of each curve is calculated using Origin software, as shown in Figure 6. A larger function curvature corresponds to a steeper function image, i.e., a greater curve curvature. As Figure 6 shows, the curvature of curve 2 is larger than that of curve 3 and curve 4, the tooth angle is sharper, and the cutting effect is better. Based on the analysis of the second derivative and curvature of the fitting curve of the cutting teeth, the cutting teeth corresponding to curve 2 were selected for use as the edge curve of the rotating cutter, and the cutting teeth are defined as the main cutting teeth.

To simplify the design of the fitting curve and consider the cutter's operational performance, based on the change law of the cutting edge and supporting edge curve of the cutting teeth, a cubic quaternion was finally determined to optimize the fitting of the cutting edge and supporting edge. The fitting curve is shown in Figures 7(a) and 7(b). The equations are as follows:

$$
\begin{aligned}
& y_{1}=-0.62336 x^{3}+2.44716 x^{2}-2.62852 x+1.18255 \\
& y_{2}=28.21302 x^{3}-146.1442 x^{2}+253.30217 x-146.4319
\end{aligned}
$$




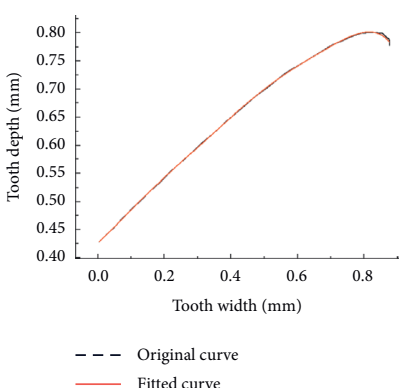

(a)

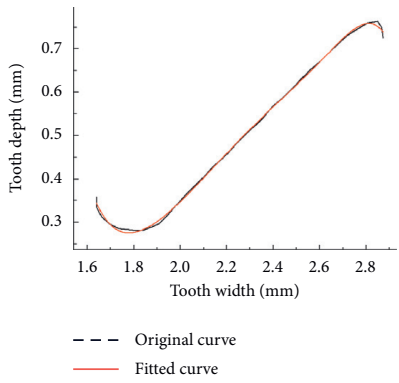

(e)

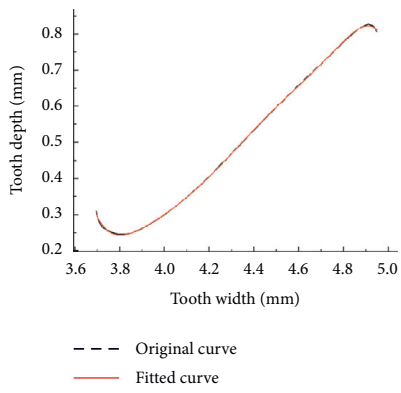

(i)

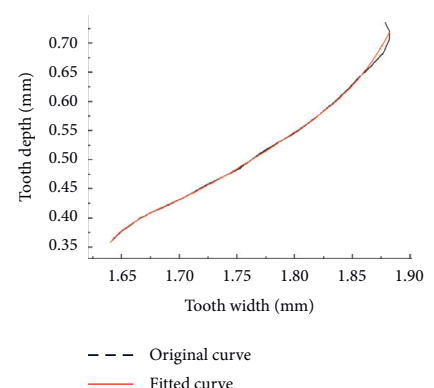

(b)

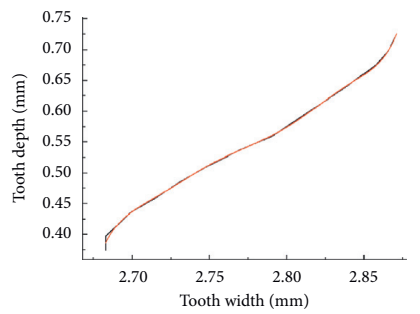

- - - Original curve

(f)

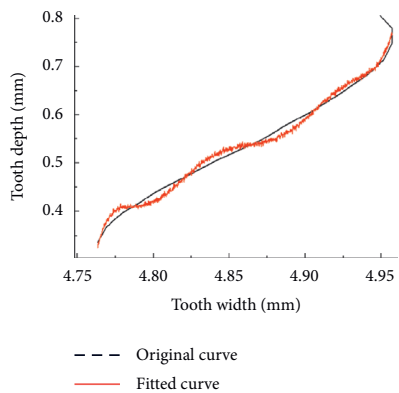

(j)

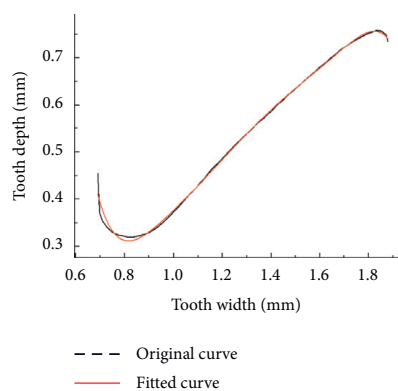

(c)

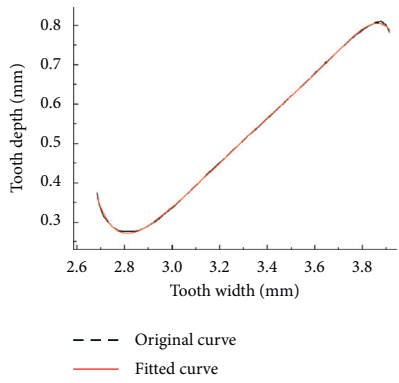

(g)

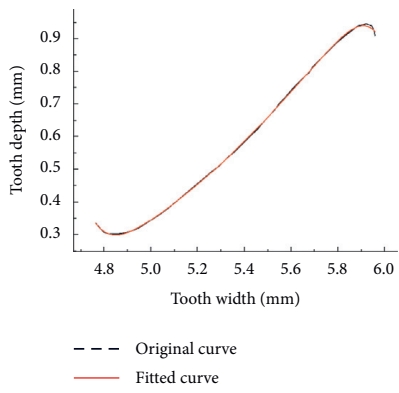

(k)

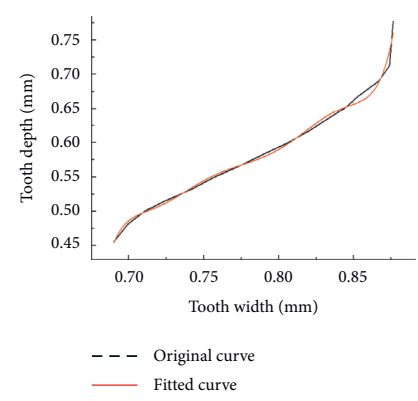

(d)

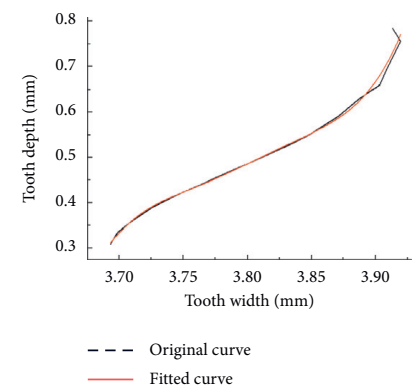

(h)

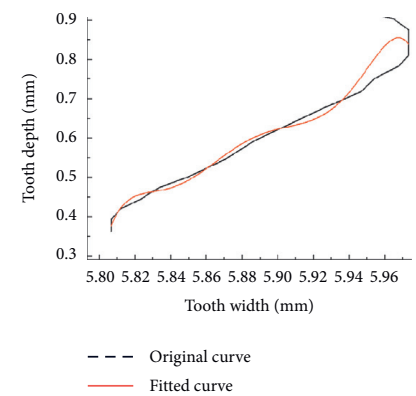

(l)

FIGURE 4: Curve fitting of the cutting tooth of the mantis forelimb. (a) Curve 1 cutting edge fitting. (b) Curve 1 supporting edge fitting. (c) Curve 2 cutting edge fitting. (d) Curve 2 supporting edge fitting. (e) Curve 3 cutting edge fitting. (f) Curve 3 supporting edge fitting. (g) Curve 4 cutting edge fitting. (h) Curve 4 supporting edge fitting. (i) Curve 5 cutting edge fitting. (j) Curve 5 supporting edge fitting. (k) Curve 6 cutting edge fitting. (l) Curve 6 supporting edge fitting.

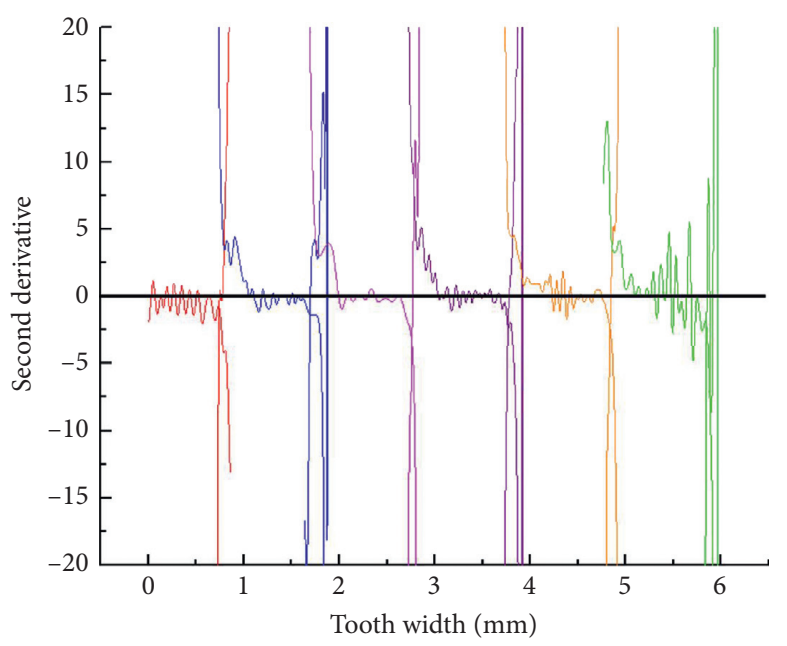

(a)

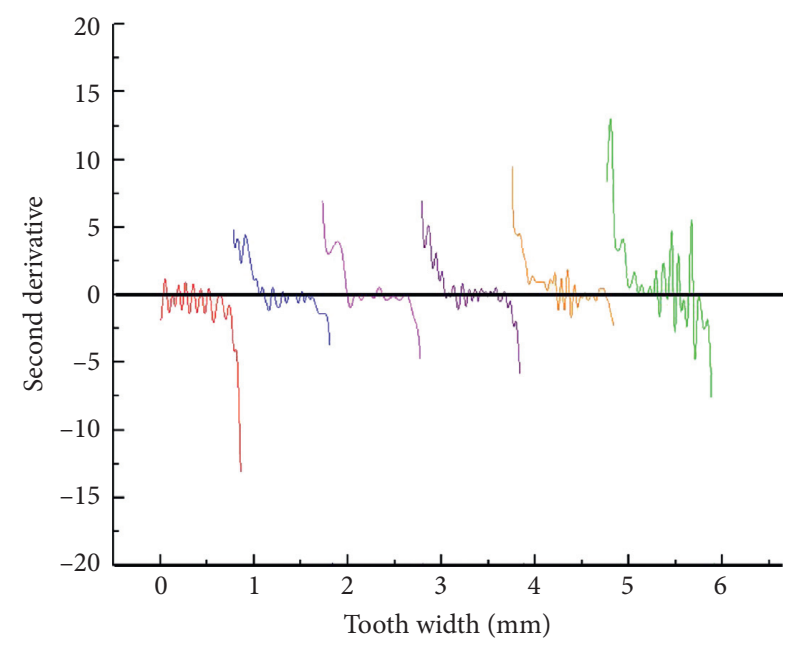

(b)

FIGURE 5: Curve fitting of the cutting teeth of the mantis forelimb after the fitting optimization. (a) Second derivative of the fitting function. (b) Second derivative of the fitting function of the cutting position. 


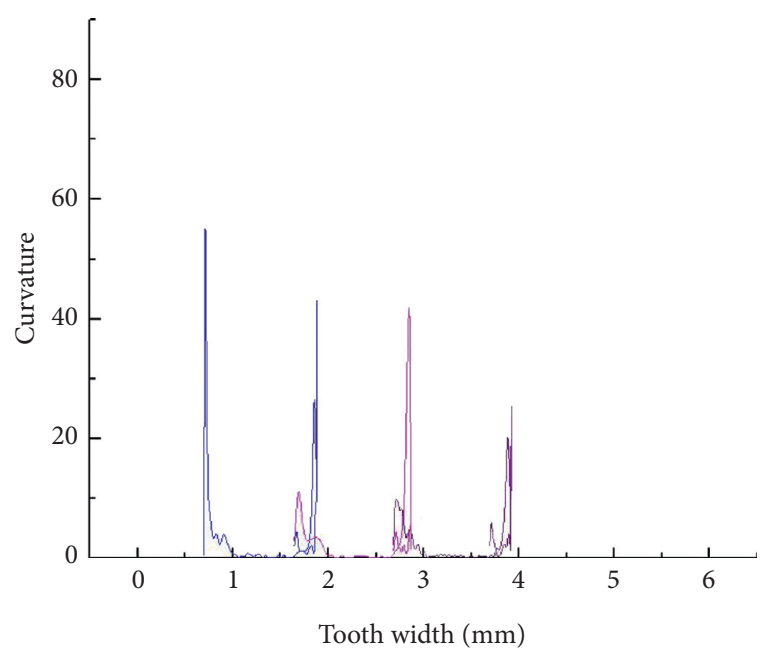

Figure 6: Curvature analysis of curves 2-4.

Here, the curve fitting degree of the cutting edge is 0.9964 , the absolute value of the residual is 0.028 , the curve fitting degree of the supporting edge is 0.99272 , and the absolute value of the residual is 0.037 . This approach intuitively shows that the curve fitting effect of the equation is good, making it suitable for processing and production. In Figure $7(\mathrm{c})$, the cutting edge curve and supporting edge curve after fitting optimization are drawn in the same coordinate system. These results show that the fitting curve of the main cutting teeth of the mantis forelimb tibia has been maintained.

The bionic single-disc rotating cutter and straight fixed cutter are the main cutting parts of the carrot harvester, and the tooth shape was designed to match the fitting curve of the main cutting teeth of the mantis forelimb. This sharp serrated structure can quickly cut stems and leaves; its blade is abrasion resistant and has a certain self-sharpening ability [23-25], as shown in Figure 8 . To ensure the cutting quality and improve the service life of the machine, the structural parameters should be reasonably designed (i.e., the diameter $D$, the number of teeth $z$, the thickness $H$, the tooth depth $h$ and the edge angle $\alpha$ of the single-disc rotating cutter, and the tooth depth $H_{1}$ of the straight fixed cutter).

To ensure that the disc cutter teeth are evenly distributed along the edge of the cutter head and avoid half teeth, a mathematical model of the disc cutter diameter and disc cutter teeth was established $[13,26]$ :

$$
\begin{gathered}
\pi D=j x_{1} z, \\
j=\frac{h}{y_{1}},
\end{gathered}
$$

where $j$ is the equal ratio magnification of the cutting teeth fitting curve, $x_{1}$ is the fitting curve width of the cutting teeth before amplification $(1.2 \mathrm{~mm})$, and $y_{1}$ is the height of the fitting curve of the cutting teeth before amplification $(0.4 \mathrm{~mm})$.
To ensure that the disc cutter teeth cut smoothly, the tooth depth should be greater than or equal to the diameter of the carrot stem fruit junction. Based on carrot physical characteristics, the maximum diameter is $14.21 \mathrm{~mm}$; therefore, $h \geq 14.21 \mathrm{~mm}$, and the tooth depth is $h=15 \mathrm{~mm}$. The equal ratio magnification of the cutting teeth fitting curve is $j=37.5$. According to (3),

$$
D=\frac{45 z}{\pi} \text {. }
$$

When the rotation speed of the disc cutter is constant, the larger the diameter of the disc cutter is, the more the teeth cutting at the same time are, and the better the cutting effect is. According to the principle of the best installation position of the disc cutter, the disc cutter has a designed diameter of $D=300 \mathrm{~mm}$; then, the number of disc cutter teeth is $z=21$. The smaller the edge angle is, the sharper the edge is, and the better the cutting effect is. However, if the cutting edge angle is too small, the rigidity of the disc cutter will be reduced, and a creeping phenomenon can easily occur. The best selection range for the edge angle is $10 \sim 15^{\circ}$. To ensure the cutting quality of the disc cutter, a blade angle of $\alpha=10^{\circ}$ is designed.

To ensure the flatness of the cutting surface, the disc cutter turns by one tooth to cut a single carrot; thus, the time taken for the carrot stem and leaf to pass through the cutting area should be greater than the time required for the disc cutter to turn by one tooth. The mathematical model of the disc cutter speed and disc cutter teeth is established as follows [23]:

$$
\frac{1}{n z} \leq \frac{x_{1} j}{v_{c}}
$$

where $v_{c}$ is the linear speed of the clamping conveyor belt, $\mathrm{m} /$ s.

According to (6), to ensure that the carrot can be clamped and smoothly pulled out of the soil, the speed of the clamping conveyor belt must be greater than the forward speed of the carrot combine harvester; therefore, $v_{c}>0.7 \mathrm{~m} /$ s. The disc cutter speed is $n \geq 45 \mathrm{r} / \mathrm{min}$.

To calculate the thickness of a single-disc dynamic cutter, the motion of the cutter when cutting stems and leaves is approximated to a circular motion.

$$
\begin{gathered}
E=J \omega^{2} C_{s}, \\
\left\{\begin{array}{l}
J=m r^{2}, \\
m=\frac{\pi}{4} D^{2} H \rho,
\end{array}\right.
\end{gathered}
$$

where $E$ is the energy generated by the disc cutter, $J ; J$ is the moment of inertia of the disc cutter, $\mathrm{kg} / \mathrm{mm}^{2} ; \omega$ is the angular velocity of the disc cutter, $\mathrm{rad} / \mathrm{s} ; C_{s}$ is the velocity fluctuation coefficient, taken as $0.64 ; m$ is the mass of the disc cutter, $\mathrm{kg} ; r$ is the radius of disc cutter, $\mathrm{mm} ; \rho$ is the disc cutter density, $\mathrm{kg} / \mathrm{mm}^{3}$; and the material is $65 \mathrm{Mn}$, which is $7.85 \times 10^{-6} \mathrm{~kg} / \mathrm{mm}^{3}$. 


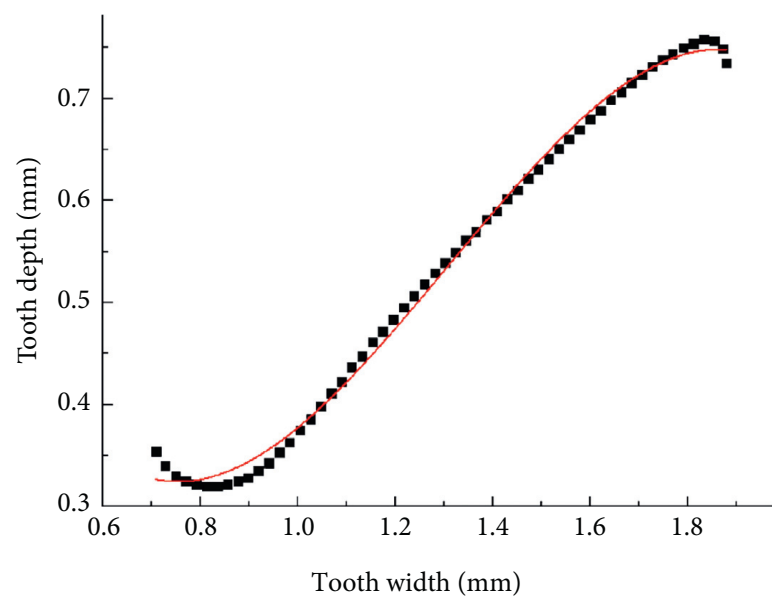

- Original point _ Fitted curve

(a)

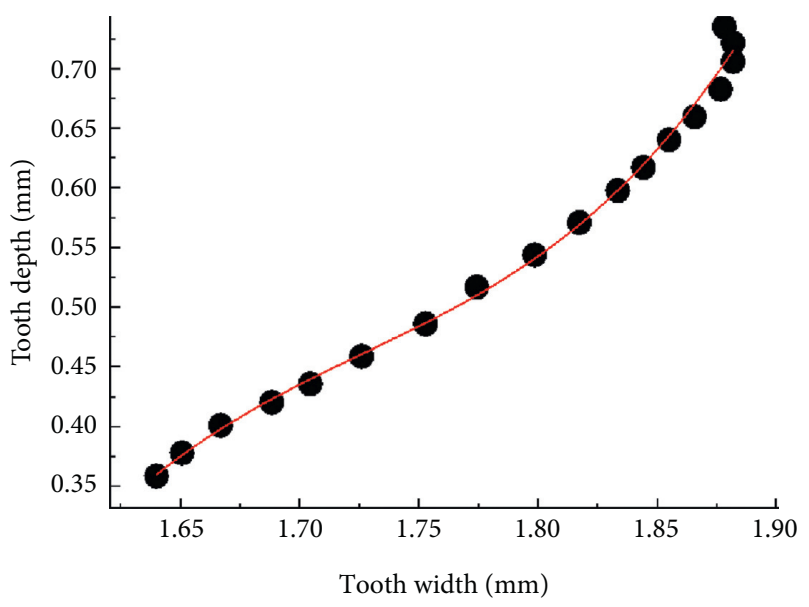

- Original point

_ Fitted curve

(b)

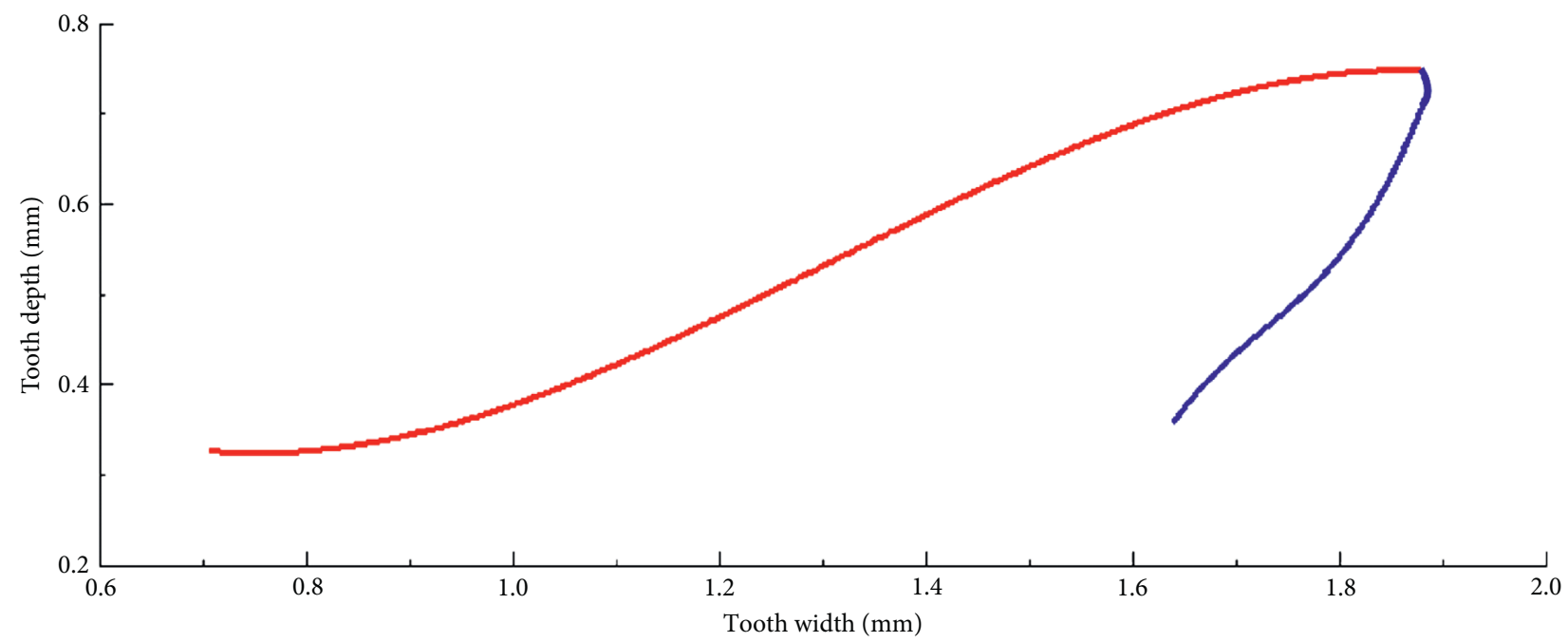

(c)

FIGURE 7: Curve fitting of the cutting tooth of the mantis forelimb after the optimization. (a) Curve fitting of cutting edge. (b) Curve fitting of supporting edge. (c) Combination of cutting edge and supporting edge.

By combining (7) and (8), we obtain the following results:

$$
H=\frac{4 E}{\pi^{3} n^{2} D^{4} \rho C_{s}} \text {. }
$$

Then, the average energy required to cut a single carrot by the disc cutter meets the following mathematical model:

$$
E_{a}=F r \psi,
$$

where $F$ is the cutting force, $\mathrm{N}$, and $\Psi$ is the rotation angle (in radians) of the disc cutter by one tooth.

A bench test showed that the cutting force required for carrot stems and leaves is $13 \sim 50 \mathrm{~N}$, the number of teeth of the disc cutter is 21 , and the arc of one tooth is $2 \pi / 21 \mathrm{rad}$. The average energy $e$ required by the disc cutter to cut each carrot is equal to the energy $E_{a}$ produced by the disc cutter when cutting. The rotation speed of the disc cutter is $n \geq 45 \mathrm{r} / \mathrm{min}$. Equations (9) and (10) can be combined and simplified to obtain $H \leq 3.29 \mathrm{~mm}$. Based on the actual processing and manufacturing operability needs, the disc cutter is designed with a thickness of $H=3 \mathrm{~mm}$.

The main function of the straight fixed cutter is to form a cutting pair with the single-disc rotating cutter; the straight cutter plays an auxiliary role during the cutting process. The tooth shape of the bionic straight fixed cutter is designed to match the outer contour curve of the main cutting teeth of the mantis forelimb, and the bionic fitting curve is magnified proportionally to the edge of the straight fixed cutter. If the blade length is too short, the entire root of the carrot stem 


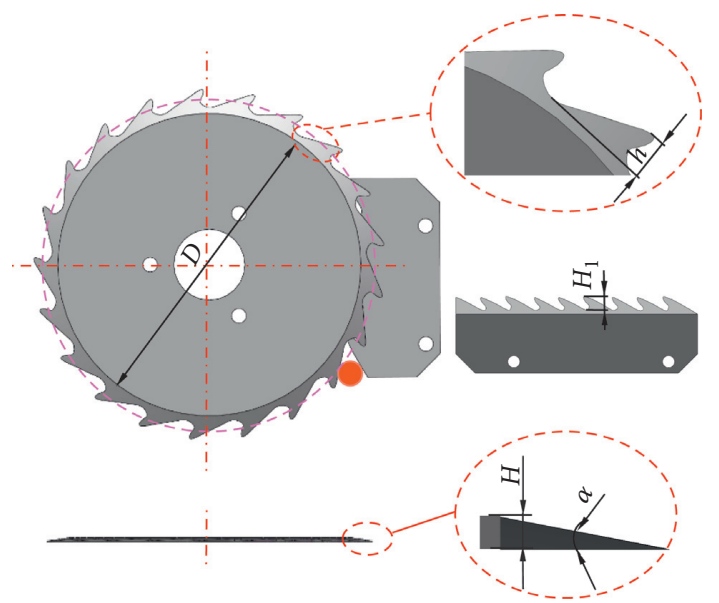

FIGURE 8: Main structural parameters of a single-disc rotating cutter and a straight fixed cutter.

and leaf cannot be fed into the cutting area, which easily results in continuous stem and leaf cutting and causes the cutting area to become congested. To ensure that the full length of the straight fixed cutter blade participates in cutting, the tooth depth $\mathrm{H} 1$ should be greater than the diameter of the carrot stem fruit joint. At the same time, the two cutters should be installed alternately from top to bottom to avoid missed cuts. The tooth depth of the straight fixed cutter should be greater than that of the single-disc rotating cutter; i.e., when the cutter tooth depth is $H_{1}>15 \mathrm{~mm}$ and the designed $H_{1}=17 \mathrm{~mm}$, the fitting curve of the main cutting teeth of the mantis forelimb is magnified 42.5 times.

\subsubsection{Analysis of Critical Conditions for Smooth Cutting.} To verify that the cutting process meets the efficiency and accuracy of the cutting requirements, the cutting planes are simplified into a circle. During the cutting process, the pulling force of the conveyor belt is $T$, the normal forces perpendicular to the edges of the two cutters are $N_{1}$ and $N_{2}$, respectively, and the friction forces parallel to the edges of the two cutters are $f_{1}$ and $f_{2}$, as shown in Figure 9. To ensure that the stems and leaves will be cut only once and do not slide outward when entering the cutting area, a kinetic model of carrot stem and leaf clamping was established.

$$
\left\{\begin{array}{l}
T+f_{1} \cos \gamma+f_{2} \cos \varepsilon>N_{1} \sin \gamma+N_{2} \sin \varepsilon \\
N_{1} \cos \gamma+f_{1} \sin \gamma=N_{2} \cos \varepsilon+f_{2} \sin \varepsilon \\
f_{1}=\mu N_{1} \\
f_{2}=\mu N_{2}
\end{array}\right.
$$

where $\gamma$ is the cutting angle of the single-disc rotating cutter $\left({ }^{\circ}\right) ; \varepsilon$ is the cutting angle of the straight fixed cutter $\left(^{\circ}\right)$, taking $35^{\circ}$ as the value; and $\mu$ is the friction coefficient between the carrot stem and the cutter.

From the bench test results, the friction coefficient between the carrot stems and cutter is $0.3-0.6$, and the cutting resistance of the stems is $13-50 \mathrm{~N}$. According to (11), it can be concluded that

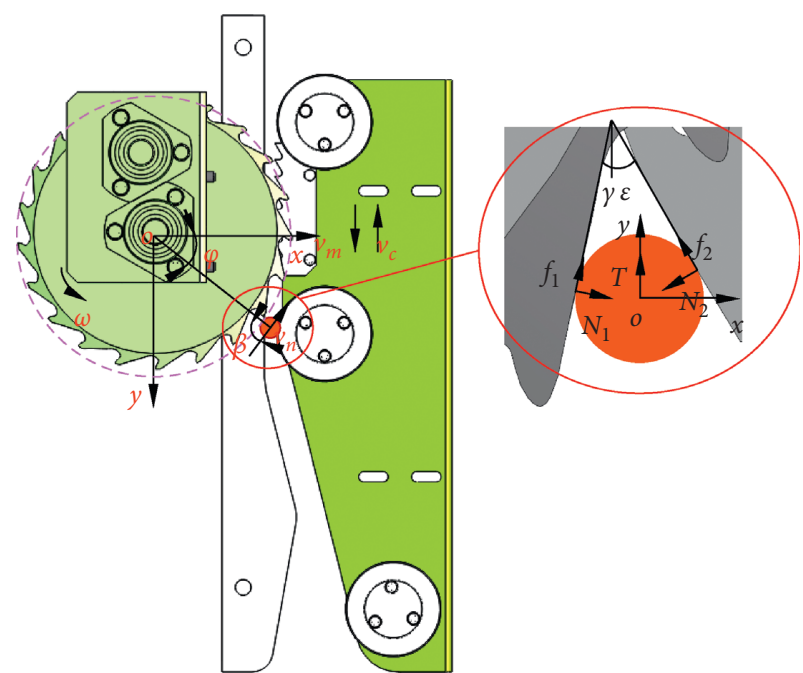

Figure 9: Dynamic and kinematic analysis of smooth cutting.

$$
T>\frac{581(5 \sin \gamma-3 \cos \gamma)}{10(5 \cos \gamma+3 \sin \gamma)}+\frac{39}{10} .
$$

From the bench test results, the tensile force of carrot stems and leaves is $87-346 \mathrm{~N}$. To avoid breakage of stems and leaves by the clamping conveyor belt during the cutting process, the pulling force $T$ of the clamping conveyor belt should be less than the tensile force of the stems and leaves. According to (12), the cutting angle of the disc cutter is less than $87^{\circ}$, and the actual variation range of the cutting angle of the disc cutter is $0-55^{\circ}$, which satisfies the requirements of the cutting angle range of the disc cutter and enables the precise cutting of the carrot stems and leaves.

To further verify that the cutting effect of the bionic cutter is better than that of a conventional cutter, the rotating center of the disc cutter is set as the origin of the coordinate system, the forward direction of the machine is the $y$-axis direction, the horizontal direction is perpendicular to the $x$-axis direction of the machine's forward motion, $v_{n}$ is the linear speed of the disc cutter, and $\beta$ is the sliding angle of the disc cutter, as shown in Figure 9. The sliding cutting angle degree is the same as that of the serrated angle of the main cutting teeth of the mantis forelimb; i.e., $\beta=55^{\circ}$. The larger the cutter sliding angle is, the smaller the resistance generated during cutting, and the better the cutting effect. The sliding angle of the disc cutter in this design is larger than that of the disc cutter used in existing carrot combine harvesters; thus, it has a better sliding cutting effect.

The vertical velocity $v_{y}$ is the main factor that influences the cutting effect of carrot stems and leaves. The results showed that the cutting time for large $v_{y}$ carrots was too short; the cutting tool was unable to complete the cut in time, and the net cutting was reduced, making the friction time between the stems and the machine too long and reducing the flatness of the cutting surface. A kinematic analysis was performed for the single carrot cutting process. The cutting time was $t$, and a mathematical model of the motion point was established as follows: 


$$
v_{y}=\frac{\mathrm{d} y}{\mathrm{~d} t}=v_{m}-\pi n D \cos \lambda \cos (\phi-2 \pi n t)-v_{c} \cos \lambda
$$

where $v_{m}$ is the forward speed of the machine, $\mathrm{m} / \mathrm{s}$ (taken as $0.7 \mathrm{~m} / \mathrm{s}) ; \lambda$ is the installation angle between the disc cutter and the ground $\left({ }^{\circ}\right)$ (taken as $\left.30^{\circ}\right) ; \varphi$ is the initial angle of the cutting point, rad; and $v_{c}$ is the linear speed of the clamping conveyor belt, $\mathrm{m} / \mathrm{s}$.

As (12) shows, the rotation speed of disc cutter $n$ and linear speed $v_{c}$ of the clamping conveyor belt are the main factors that affect the change in vertical closing speed $v_{y}$. Therefore, the linear speed of the clamping conveyor belt and rotation speed of the disc cutter were adopted as the variable factors for a series of experimental studies conducted during the test phase to verify the superior performance of the bionic cutter optimized in this study.

2.3. Bench Test and Field Experiment. To further test the influence of various factors on the performance of bionic cutting tools for the cutting device, to compare its reliability and stability with the conventional tool, and to verify the operational qualities, a bench single-factor test, a bench comparative test, and a field experiment were conducted.

From September to October 2019, the single-factor and comparative tests were performed at the Laboratory of Intelligent Agricultural Machinery Equipment at Northeast Agricultural University. The "red ginseng 7-inch" carrot variety, which is widely planted in Heilongjiang Province, was selected for this test. During the test, the power for the clamping and conveying device was provided by the motor, and the carrots were manually and evenly transported up to the cutting device. A gear shaft drives the disc cutter to rotate to complete the cutting process, as shown in Figure 10(a). Based on the previous theoretical analysis, the bench test and the actual production requirements, the linear speed of the clamping conveyor belt, and the rotation speed of the disc cutter are the main factors that affect carrot cutting quality. However, the linear speed cannot be accurately measured; instead, it must be converted into the rotational speed of the clamping belt pulley [27]. The conversion relationship for speed between the linear and the clamping conveyor pulley is as follows:

$$
v_{c}=\pi n_{c} D,
$$

where $v_{c}$ is the linear speed of the clamping conveyor belt, $\mathrm{m} /$ $s ; n_{c}$ is the rotating speed of the clamping conveying pulley, $\mathrm{r} / \mathrm{min}$; and $D_{c}$ is the diameter of clamping conveying pulley, $\mathrm{mm}$, which is $235 \mathrm{~mm}$ in this case.

During the single-factor test, the change law of the working effect was analyzed under the following single-disc cutter and straight cutter working conditions: $57-147 \mathrm{r} / \mathrm{min}$ (57 r/min, $72 \mathrm{r} / \mathrm{min}, 87 \mathrm{r} / \mathrm{min}, 102 \mathrm{r} / \mathrm{min}, 117 \mathrm{r} / \mathrm{min}, 132 \mathrm{r} /$ $\mathrm{min}$, and $147 \mathrm{r} / \mathrm{min}$ ) for the clamping conveyor pulley and $45-225 \mathrm{r} / \mathrm{min}(45 \mathrm{r} / \mathrm{min}, 75 \mathrm{r} / \mathrm{min}, 105 \mathrm{r} / \mathrm{min}, 135 \mathrm{r} / \mathrm{min}$, $165 \mathrm{r} / \mathrm{min}, 195 \mathrm{r} / \mathrm{min}$, and $225 \mathrm{r} / \mathrm{min}$ ) for the single-disc cutter. During the comparative testing process, the current common domestic single-disc cutter and straight cutter were selected as benchmark references [28, 29]; the cutting performance comparison test was performed, as shown in Figure 10(b). The bench test was repeated 5 times under various working conditions, and the average value was taken as the test result.

To further test the performance of the optimized stemand leaf-cutting device under complex and changeable environments, field experiments were conducted in a Qingfeng Village carrot-planting area $\left(126.68^{\circ} \mathrm{E}, 45.72^{\circ} \mathrm{N}\right)$ in Harbin City from October to November 2019, as shown in Figure 11. The carrot variety was "red ginseng 7-inch," the working area was $1000 \mathrm{~m}^{2}$, the soil type was adhesive black loam, the average soil firmness was $786 \mathrm{kPa}$, the average soil moisture content in the cultivated layer was $11.63 \%$, and the temperature was $18^{\circ} \mathrm{C}$. In the carrot harvest environment, the ridge spacing was $680 \mathrm{~mm}$, the ridge height was $130 \mathrm{~mm}$, and the plant spacing was $100-120 \mathrm{~mm}$. The test prototype was a knapsack-type carrot combine harvester equipped with an optimized bionic rotating fixed cutter, and the driving machine was a Zoomlion LA1002-A crawler tractor. The field experiment machine ran well, and the operators were skilled, meeting the requirements of straight-line driving in field operation. The field was divided into three parts: a start-up adjustment area, an effective experiment area, and a stop operation area. The adjustment area and stop area were $10 \mathrm{~m}$. The forward speed of the tractor was set to $2.5 \sim 3.0 \mathrm{~km} / \mathrm{h}$, the rotation speed of the clamping conveyor pulley was $102 \mathrm{r} / \mathrm{min}$, and the rotation speed of the disc cutter was $165 \mathrm{r} / \mathrm{min}$. Manual sampling was conducted immediately after operation, and the manual measurement statistics were obtained according to GB/T5262-2008 "general provisions for determination methods of test conditions of agricultural machinery" [30]. Ten rows were randomly selected to measure the $100 \mathrm{~m}$ harvest distance. The average values of the total number of carrots, damaged carrots, and unharmed carrots were recorded as the test results.

The results of this investigation showed that the length of the remaining carrot stems and leaves after cutting was greater than $30 \mathrm{~mm}$, which can accelerate the carrots decay rate. Damage to carrot roots and stems and the cutting regularity of stems and leaves are the main factors that determine the economic value of harvested carrots [31]. Therefore, the damage of rhizomes, the net cutting of stems and leaves, and the flatness of the cutting surface were selected as the evaluation indices for the results of the bench test and field experiment. Because no international standard for carrot harvesting and cutting exists, this study defines the cutting state as follows: skin shedding at the junction of the carrot stem and root, and harm to pulp tissue are considered as damaged carrots, as shown in Figure 12(a). If the length of the remaining carrot stems and leaves exceeds $30 \mathrm{~mm}$, then the stems and leaves are not cleanly cut, as shown in Figure 12(b). After deducting unclean cuttings, an uneven cutting surface is considered as the "flatness of the cutting surface," as shown in Figure 12(c).

After the stems and leaves were cut, the total number of carrots was collected and counted, and the number of carrots 


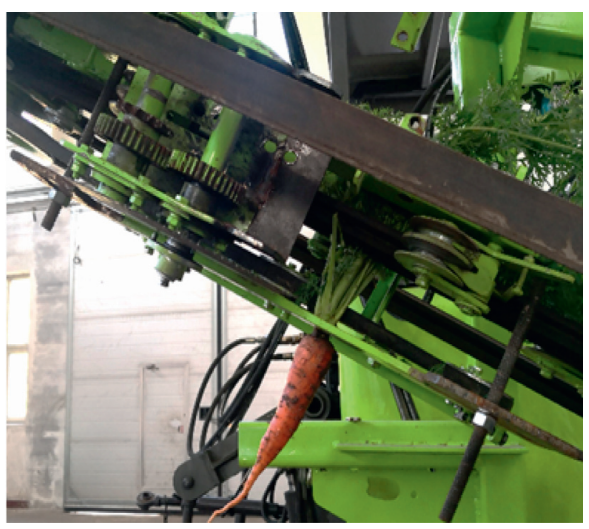

(a)

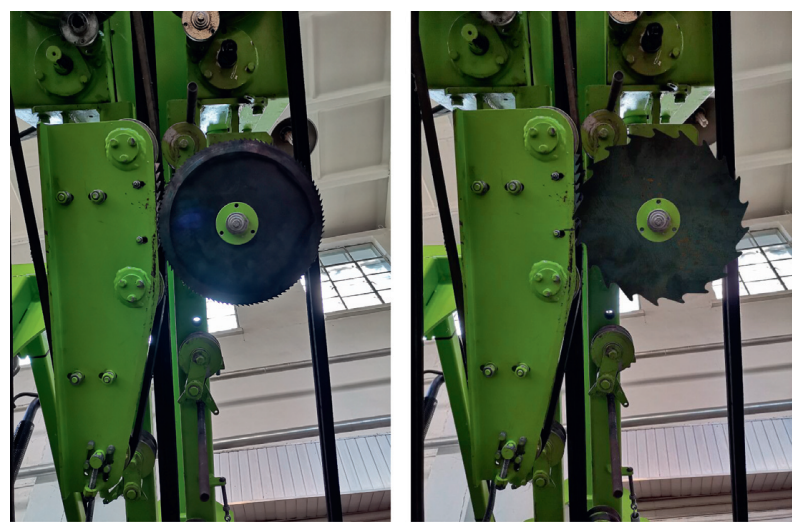

(b)

Figure 10: Bench test. (a) Cutting status. (b) Comparison between conventional tool and bionic tool.
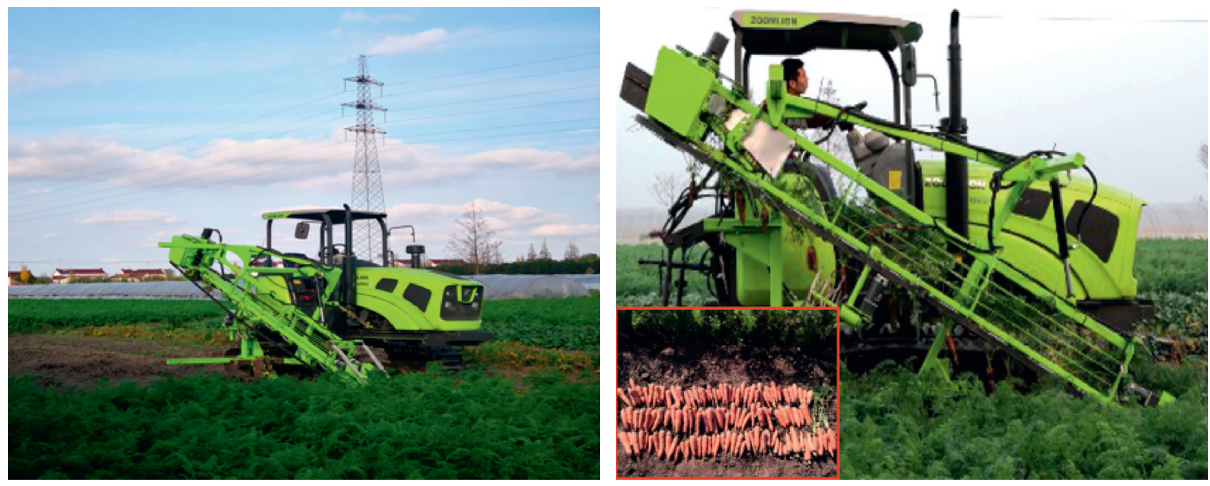

FIGURE 11: Field experiment.

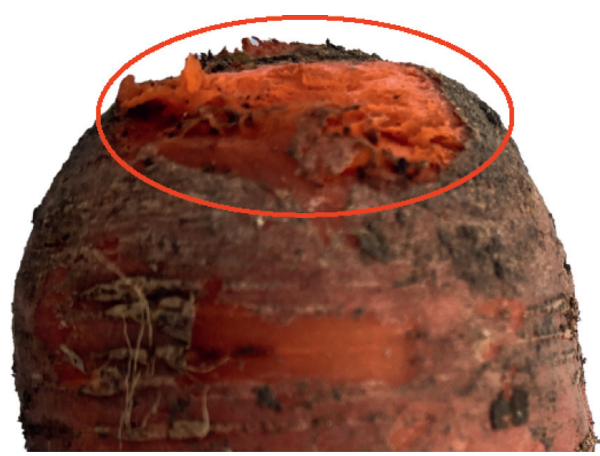

(a)

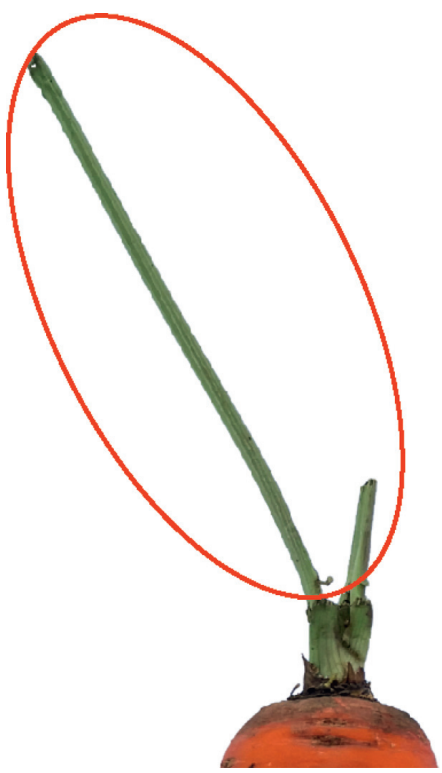

(b)

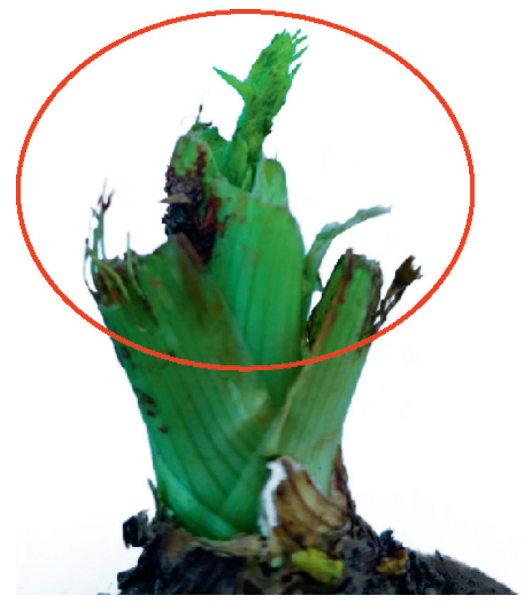

(c)

FIgURE 12: Common stem- and leaf-cutting problems. (a) Rhizomes damage. (b) Stem and leaf residue. (c) Uneven cutting. 
with damaged rhizomes, clean stems and leaves, and smooth cutting surfaces was identified. The methods to calculate the relevant evaluation indices are as follows:

$$
\left\{\begin{array}{l}
P=\frac{s_{0}}{W} \times 100 \% \\
Q=\frac{s_{1}}{W} \times 100 \% \\
Z=\frac{s_{2}}{W} \times 100 \%
\end{array}\right.
$$

where $P$ is the percentage of damage to the rhizomes, \%; $Q$ is the net cutting percentage of stems and leaves, $\% ; Z$ is the flatness percentage of the cutting surface, $\%$; $s_{0}$ is the number of damaged rhizomes, root; $s_{1}$ is the net cutting number of stems and leaves, root; $s_{2}$ is the flat number of cutting surfaces, root; and $W$ is the total number of carrots, root.

\section{Results and Analysis}

3.1. Results and Analysis of the Single-Factor Test on the Bench. The speed priority control test of the clamping conveyor pulley was analyzed. Using the disc cutter speed of $135 \mathrm{r} / \mathrm{min}$ and clamping conveyor pulley speed of $57-147 \mathrm{r} / \mathrm{min}$, a statistical analysis was conducted regarding the rhizome damage, net cutting of stems and leaves, and flatness of the cutting surface, as shown in Figure 13. In Figure 13(a), when the speed of the clamping conveyor pulley increases, the rhizome damage gradually decreases. When the speed reaches $102 \mathrm{r} / \mathrm{min}$, the average rhizome damage is $2.86 \%$. When the speed reaches $147 \mathrm{r} / \mathrm{min}$, the average rhizome damage decreases to $1.31 \%$. At speeds above $102 \mathrm{r} / \mathrm{min}$, the rhizome damage continues to gradually decrease; i.e., the slope of the curve gradually decreases. In Figure 13(b), when the speed of the clamping conveyor pulley increases, the average cutting of the stems and leaves is $98.21 \%$ at a speed of $57 \mathrm{r} / \mathrm{min}$ but decreases to $92.82 \%$ when the speed increases to $102 \mathrm{r} / \mathrm{min}$. At speeds greater than $102 \mathrm{r} / \mathrm{min}$, the net cutting of stems and leaves continues to gradually decrease, and the change trend becomes sharper; i.e., the curve slope gradually increases. Figure 13(c) shows that when the clamping conveyor pulley speed increases, the flatness of the cutting surface first increases and subsequently decreases. When the speed is $102 \mathrm{r} /$ min, the maximum average flatness of the cutting surface is $85.39 \%$. At speeds above $102 \mathrm{r} / \mathrm{min}$, the flatness of the cutting surface gradually decreases. Based on these tests, the regression equations of the rhizome damage, net cutting of stems and leaves, and flatness of the cutting surface with the rotation speed of the clamping conveyor pulley were obtained, and the corresponding determination coefficients $R^{2}$ were $0.9977,0.9913$, and 0.9892 , respectively.

The results show that the rotation speed of the clamping conveyor belt pulley has a substantial effect on the cutting quality. As the belt pulley speed increases, the carrot stems and leaves contact time with the rotating and fixed cutters becomes shorter, and the ratio of feeding speed to cutting speed increases, which leads to the stems and leaves being transported away from the cutting area without undergoing sufficient cutting time. When the rotation speed of clamping conveyor pulley is too low, the peripheral stems and leaves contact the rotating and fixed cutters for a longer time, which become worn during cutting, reducing the flatness after cutting. At higher clamping conveyor pulley rotation speeds, the ratio of feeding speed to disc cutter speed increases, resulting in part of the carrot stems and leaves being pulled off without cutting. The comprehensive analysis shows that the clamping conveyor pulley speed should be set to $102 \mathrm{r} / \mathrm{min}$ when the speed priority control strategy is adopted.

The speed priority control test results of the disc cutter were analyzed. Under the working conditions with a clamping belt pulley rotational speed of $102 \mathrm{r} / \mathrm{min}$ and a disc cutter speed of $45-225 \mathrm{r} / \mathrm{min}$, the rhizome damage, net cutting of the stems and leaves, and flatness of the cutting surface were statistically analyzed, as shown in Figure 14. In Figure 14(a), with the increase in disc cutter speed, the rhizome damage gradually decreases. When the speed is $165 \mathrm{r} / \mathrm{min}$, the rhizome damage is $1.97 \%$. When the speed is greater than $165 \mathrm{r} / \mathrm{min}$, the decreasing trend of the rhizome damage gradually slows; i.e., the slope of the curve gradually decreases. In Figure 14(b), when the disc cutter speed increases, the net cutting of the stems and leaves gradually increases and finally tends to become flat. When the speed reaches $165 \mathrm{r} / \mathrm{min}$, the net cutting of stems and leaves is 94.87\%; when the speed reaches 225 ( $\mathrm{min}$ ), the net cutting of stems and leaves is $95.74 \%$. When the speed exceeds $165 \mathrm{r} /$ min, the decreasing trend of the net cutting of stems and leaves gradually diminishes; i.e., the slope of the curve more gradually decreases. Figure 14(c) shows that when the disc cutter speed increases, the flatness of the cutting surface gradually increases. When the speed increases from $165 \mathrm{r} /$ min to $225 \mathrm{r} / \mathrm{min}$, the flatness of the cutting surface increases from $89.59 \%$ to $91.48 \%$. Based on these results, the regression equations of the mean value of the rhizome damage, net cutting of the stems and leaves, and flatness of the cutting surface with the disc cutter speed were obtained. The corresponding determination coefficients $R^{2}$ are $0.9978,0.9952$, and 0.9936 , respectively.

The results show that the number of times the carrot leaves were cut increased and that the cutting time decreased as the disc cutter speed increased. This increased speed reduces the phenomenon where the stems and leaves are removed from the cutting area too soon or pulled off by gravity without cutting, which reduces the rhizome damage and gradually increases the net cutting of stems and leaves and the flatness of the cutting surface. Finally, considering the overall cutting efficiency, the quality requirements, the power consumption, and other factors, the disc cutter speed was set to $165 \mathrm{r} / \mathrm{min}$ for the disc cutter speed priority control strategy.

3.2. Results and Analysis of the Comparative Bench Test. Taking a conventional single-disc rotating cutter and a straight fixed cutter with the common tooth profile as a 


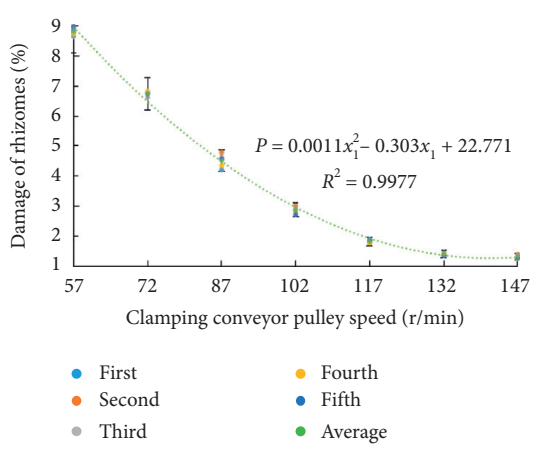

(a)

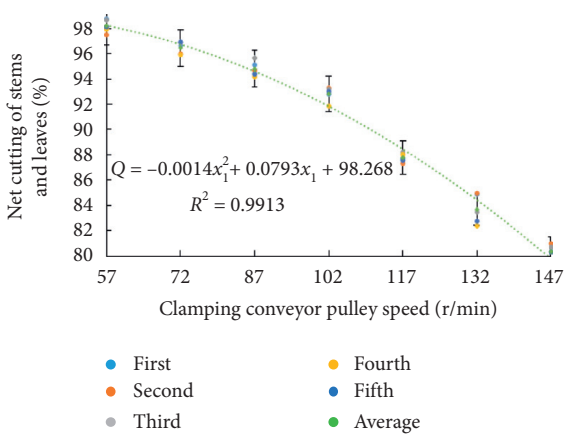

(b)

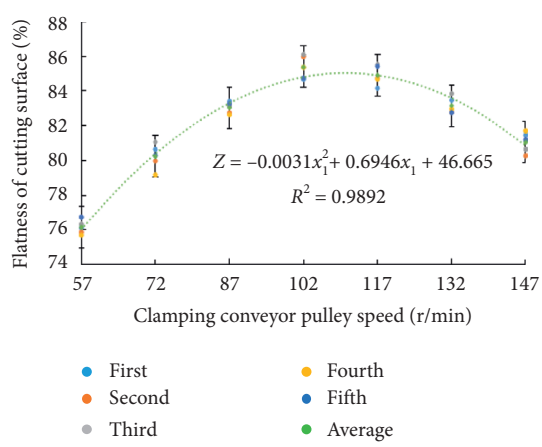

(c)

Figure 13: Analysis of the speed priority control strategy for the clamping conveyor pulley. (a) Regularity of damage of the rhizomes. (b) Regularity of the net cutting of the stems and leaves. (c) Regularity of the flatness of the cutting surface.

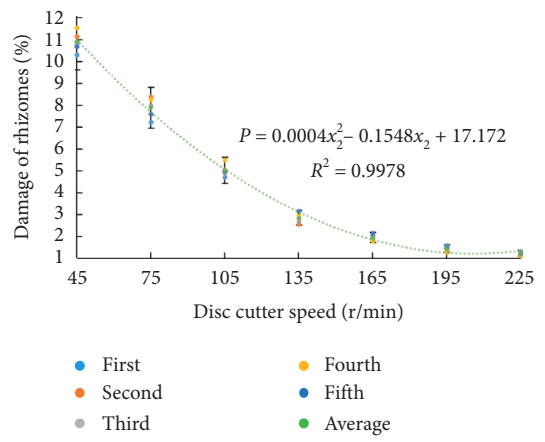

(a)

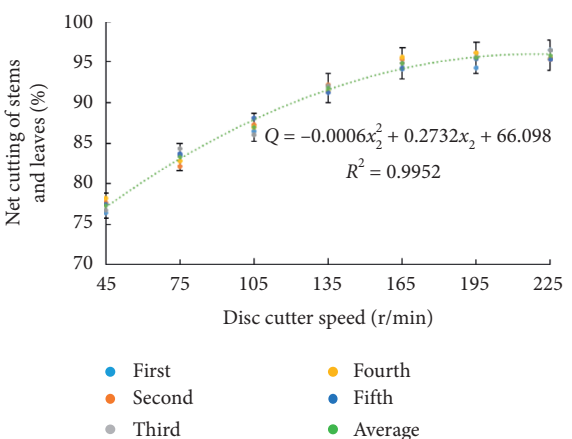

(b)

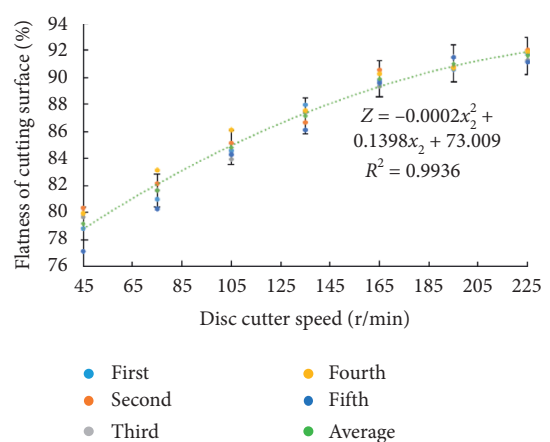

(c)

Figure 14: Analysis of the speed priority control strategy for the disc cutter. Regularity of the (a) rhizome damage, (b) net cutting of stems and leaves, and (c) flatness of the cutting surface.

reference, a comparative bench test compared the conventional system with the proposed system under the working conditions with a clamping belt pulley rotational speed of $102 \mathrm{r} / \mathrm{min}$ and a disc cutter speed of $165 \mathrm{r} / \mathrm{min}$. The growing carrots in this experiment were simultaneously planted in the same experimental field. The results of an artificial screening showed that the stem and leaf sizes of carrots were basically consistent. In total, 1,000 carrots were cut in each group, and the corresponding evaluation indices were determined, as shown in Table 1.

From Table 1, under working conditions, the cutting performance of the optimized bionic fixed cutter is clearly better than that of the conventional cutter; the overall stability is better, and the coefficient of variation of the evaluation index is small. The average rhizome damage was $3.11 \%$, an improvement of $6.07 \%$. The net cutting of stems and leaves was $94.83 \%$, an improvement of $10.66 \%$. The flatness of the cutting surface was $86.68 \%$, an improvement of $2.28 \%$. This bench comparison shows that the working efficiency of the harvesting tool continuously improves; i.e., when the rotation speeds of the clamping conveyor pulley and disc cutter increase, the net cutting and cutting surface flatness of the optimized bionic cutter substantially outperform those of the conventional cutter, which reflects the rationality and superiority of the proposed design.
3.3. Results and Analysis of the Field Experiment. The results show that the rhizome damage, net cutting of stems and leaves, and flatness of the cutting surface were $4.01 \%$, $92.05 \%$, and $84.05 \%$, respectively. Moreover, the field experiment had slightly lower quality than the bench test, which was mainly due to irregular carrot movements during clamping, transportation, and cutting due to the effects of ground conditions during field operation, which reduced the device alignment and cutting effects. Carrot cutting also results in a certain amount of collision damage during the collection process, but the overall error was less than $15 \%$, which is within the acceptable range. These results have a practical reference value, and the device worked well overall.

\section{Conclusions and Future Work}

In this study, the problems of high rhizome damage, low net cutting of stems and leaves, and uneven cutting surfaces are the major problems during the cutting process of carrot combine harvesting. A bionic design and parameter optimization for the rotating and fixed cutters of cutting devices were conducted to provide an important theoretical reference to optimize the performance of carrot combine harvesters and improve similar mechanical cutters. The main conclusions are as follows: 
TABLE 1: Results of the bench comparison test.

\begin{tabular}{|c|c|c|c|c|c|c|}
\hline \multirow{3}{*}{ Order } & \multicolumn{6}{|c|}{ Index } \\
\hline & \multicolumn{3}{|c|}{ Optimized bionic cutting device } & \multicolumn{3}{|c|}{ Conventional cutting device } \\
\hline & $\begin{array}{c}\text { Rhizomes } \\
\text { damage (\%) }\end{array}$ & $\begin{array}{l}\text { Net cutting of stems } \\
\text { and leaves (\%) }\end{array}$ & $\begin{array}{l}\text { Flatness of the } \\
\text { cutting surface (\%) }\end{array}$ & $\begin{array}{c}\text { Rhizomes } \\
\text { damage (\%) }\end{array}$ & $\begin{array}{l}\text { Net cutting of stems } \\
\text { and leaves (\%) }\end{array}$ & $\begin{array}{c}\text { Flatness of cutting } \\
\text { surface }(\%)\end{array}$ \\
\hline 1 & 2.88 & 96.12 & 85.72 & 9.18 & 85.65 & 79.58 \\
\hline 2 & 3.98 & 94.35 & 86.10 & 8.15 & 83.02 & 78.46 \\
\hline 3 & 3.12 & 93.63 & 84.88 & 8.12 & 84.17 & 82.34 \\
\hline 4 & 3.54 & 95.12 & 88.75 & 10.69 & 84.99 & 80.12 \\
\hline 5 & 2.01 & 94.95 & 87.94 & 9.74 & 83.02 & 81.48 \\
\hline Mean value & 3.11 & 94.83 & 86.68 & 9.18 & 84.17 & 80.40 \\
\hline
\end{tabular}

(1) The tibia curve of the mantis forelimb was extracted and optimized using the MATLAB software, and the resulting shape was applied to the cutting edge of a single-disc rotating cutter and a straight fixed cutter. The key structural parameters were determined, and kinematic and dynamic models of the cutter and carrot stems and leaves were established. The critical conditions for stable cutting were explored, and the quality and efficiency of carrot cutting were improved, which can reduce economic losses from carrots after harvesting.

(2) A platform single-factor priority control strategy test was performed. The results show that the rhizome damage and net cutting of stems and leaves increased, while the flatness of the cutting surface first increased and subsequently decreased when the rotational speed of the clamping conveyor pulley increased. When the rotation speed of the clamping conveyor pulley reached $102 \mathrm{r} / \mathrm{min}$, the rhizome damage was $2.86 \%$, the net cutting of stems and leaves was $92.82 \%$, and the flatness of the cutting surface was $85.39 \%$. When the speed of the disc cutter reached $165 \mathrm{r} / \mathrm{min}$, the rhizome damage was $1.97 \%$, the net cutting of stems and leaves was $89.59 \%$, and the flatness of the cutting surface was $91.48 \%$. The optimal cutting performance was obtained when the rotational speeds of the clamping conveyor pulley and disc cutter were $102 \mathrm{r} /$ min and $165 \mathrm{r} / \mathrm{min}$, respectively.

(3) A bench test and a field experiment were performed. The results show that the cutting performance of the optimized bionic fixed cutter is notably better than that of a conventional cutter. The rhizome damage, net cutting of stems and leaves, and flatness of the cutting surface of the proposed system were $4.01 \%$, $92.05 \%$, and $84.05 \%$, respectively, all of which satisfy the carrot harvest agronomy requirements.

For future studies, since the bionic action of the cutting device may produce part of the mechanical vibration and affect the overall harvest quality [32], this problem requires follow-up research. In addition, an intelligent control system for cutting tools will be developed to control the cutting speed of the cutter in real time based on the working conditions of the machines and tools to effectively improve the carrot harvesting quality and degree of intelligence of the machine and tool.

\section{Data Availability}

The digital data supporting this article are from previously reported studies and datasets, which have been cited.

\section{Conflicts of Interest}

The authors declare that they have no conflicts of interest.

\section{Acknowledgments}

This research was financially supported by the National Key R\&D Program of China under Grant 2017YFD0701305 and by the Provincial Key Research and Development Program of Heilongjiang Province of China under Grant GX18B026.

\section{References}

[1] J. E. Mcphee and P. L. Aird, "Controlled traffic for vegetable production: Part 1. Machinery challenges and options in a diversified vegetable industry," Biosystems Engineering, vol. 116, no. 2, pp. 144-154, 2013.

[2] J. Wang, D. Du, and J. Hu, "Vegetable mechanized harvesting technology and its development," Transactions of the Chinese Society for Agricultural Machinery, vol. 45, no. 2, pp. 81-87, 2014.

[3] X. Han, H. Chen, and G. Dun, "Analysis on situation of carrot mechanized harvesting technology," Journal of Agricultural Mechanization Research, vol. 37, no. 7, pp. 259-263, 2015.

[4] Z. Hu, B. Peng, and W. Yin, "Design and experiment on multifunctional root-tuber crops combine," Transactions of the Chinese Society for Agricultural Machinery, vol. 39, no. 10, pp. 58-61, 2008.

[5] J. Wang and S. Shang, "Development and experiment of double-row self-propelled carrots combine," Transactions of the Chinese Society of Agricultural Engineering, vol. 28, no. 12, pp. 38-43, 2012.

[6] T. Cembali, R. J. Folwell, C. D. Clary, and M. Mari, "Economic comparison of selective and nonselective mechanical harvesting of asparagus," International Journal of Vegetable Science, vol. 14, no. 1, pp. 4-22, 2008.

[7] K. Jozef and L. Norbert, "The influence of working parameters of a carrot harvester on carrot root damage," Maintenance and Reliability, vol. 39, no. 1, pp. 35-41, 2011.

[8] S. Nath, A. Kumar, I. Mani, and J. Singh, "Determination of physical and mechanical properties of carrot (Daucus carota) for designing combine harvesting mechanism," Indian Journal of Agricultural Sciences, vol. 89, no. 6, pp. 1011-1016, 2019. 
[9] R. Stopa, P. Komarnicki, and D. Szyjewicz, "Modeling of carrot root radial press process for different shapes of loading elements using the finite element method," International Journal of Food Properties, vol. 20, pp. 340-352, 2017.

[10] J. Wang, X. Li, and P. Gao, "Design and experiment of high efficiency drag reducing shovel for carrot combine harvester," Transactions of the Chinese Society for Agricultural Machinery, vol. 51, no. 6, pp. 93-103, 2020.

[11] X. Jin, X. Du, and S. Wang, "Design and experiment of stems cutting device for carrot harvester," Transactions of the Chinese Society for Agricultural Machinery, vol. 47, no. 3, pp. 82-89, 2016.

[12] G. Zeng, J. Chen, and X. Xia, "Design and experiment on pull type of tassel fruit separation for carrot," Transactions of the Chinese Society for Agricultural Machinery, vol. 49, no. 10, pp. 73-79, 2018.

[13] J. Wang, R. Guan, and P. Gao, "Design and experiment of single disc to top cutting device for carrot combine harvester," Transactions of the Chinese Society for Agricultural Machinery, vol. 51, no. 8, pp. 105-113, 2020.

[14] D. Du, J. Wang, L. Xie, and F. Deng, "Design and field test of a new compact self-propelled cabbage harvester," Transactions of the ASABE, vol. 62, no. 5, pp. 1243-1250, 2019.

[15] N. Leszczynski, "The Influence of working parameters of a carrot harvester carrot root damage," Eksploatacja I Niezawodnosc-Maintenance and Reliability, vol. 1, pp. 35-41, 2011.

[16] S. Shirwal, I. Mani, and N. Sirohi, "Development and evaluation of carrot harvester," AMA-Agricultural Mechanization in Asia Africa Latin America, vol. 46, no. 1, pp. 28-34, 2015.

[17] S. Chen, Y. Zhou, Z. Tang, and S. Lu, "Modal vibration response of rice combine harvester frame under multi-source excitation," Biosystems Engineering, vol. 194, pp. 177-195, 2020.

[18] J. Tong, W. Ji, H. Jia, D. Chen, and X. Yang, "Design and tests of biomimetic blades for soil-rototilling and stubble-breaking," Journal of Bionic Engineering, vol. 12, no. 3, pp. 495-503, 2015.

[19] Z. Chang, W. Liu, J. Tong et al., "Design and experiments of biomimetic stubble cutter," Journal of Bionic Engineering, vol. 13, no. 2, pp. 335-343, 2016.

[20] P. Oviasogle, D. Okoro, and C. Ndiokwere, "Determination of total phenolic amount of some edible fruits and vegetables," African of Journal of Biotechnology, vol. 8, no. 12, pp. 2819-2820, 2009.

[21] J. T. Goulart, R. A. Bassani, and J. W. M. Bassani, "Application based on the canny edge detection algorithm for recording contractions of isolated cardiac myocytes," Computers in Biology and Medicine, vol. 81, pp. 106-110, 2017.

[22] T. Fujinoto, T. Kawasaki, and K. Kitamura, "Canny-EdgeDetection/Rankine-Hugoniot-conditions unified shock sensor for inviscid and viscous flows," Journal of Computational Physics, vol. 396, pp. 264-279, 2019.

[23] J. Ran, S. Mu, and H. Li, "Design and test of planet gear driver of reciprocating double-acting cutter for rapeseed combine harvester," Transactions of the Chinese Society of Agricultural Engineering, vol. 36, no. 9, pp. 17-25, 2020.

[24] E. Navas, R. Femandez, and D. Sepulveda, "A design criterion based on shear energy consumption for robotic harvesting tools," Agronomy-Basel, vol. 10, no. 5, 2020.

[25] J. Chen, Y. Lian, and Y. Li, "Real-time grain impurity sensing for rice combine harvesters using image processing and decision-tree algorithm," Computers and Electronics in Agriculture, vol. 175, pp. 97-103, 2020.
[26] J. Zhao, M. Guo, M. Guo, Y. Lu, D. Huang, and J. Zhuang, "Design of bionic locust mouthparts stubble cutting device," International Journal of Agricultural and Biological Engineering, vol. 13, no. 1, pp. 20-28, 2020.

[27] K. Tian, X. Li, and C. Shen, "Design and test of cutting blade of cannabis harvester based on longicorn bionic principle," Transactions of the Chinese Society of Agricultural Engineering, vol. 33, no. 5, pp. 56-61, 2017.

[28] Z. Yu, Z. Hu, and K. Yang, "Design and experiment of root cutting device in garlic combine harvesting," Transactions of the Chinese Society of Agricultural Engineering, vol. 32, no. 22, pp. 77-85, 2016.

[29] J. Bai, S. Ma, W. Ke et al., "Experimental research on sugarcane under-the-ground basecutting," Applied Engineering in Agriculture, vol. 36, no. 3, pp. 331-339, 2020.

[30] Y. Cao, "Research on application of the Internet of things technology in financial leasing of intelligent manufacturing enterprises," The International Journal of Advanced Manufacturing Technology, vol. 107, no. 3-4, pp. 1061-1070, 2020.

[31] J. Wang, H. Tang, and J. Wang, "Optimization design and experiment on ripple surface type pickup finger of precision maize seed metering device," International Journal of Agricultural \& Biological Engineering, vol. 10, no. 1, pp. 61-71, 2017.

[32] T. Li, J. Zhou, and W. Xu, "Design and test of auto-follow row system employed in root and stem crops harvester," Transactions of the Chinese Society for Agricultural Machinery, vol. 50, no. 11, pp. 102-110, 2019. 